\title{
КЛАДЫ МЕДНЫХ МОНЕТ ДИНАСТИИ ШЕЙБАНИДОВ НА ТЕРРИТОРИИ КЫРГЫЗСТАНА
}

\author{
(C) 2018 г. А.М. Камышев, А.О. Брагин
}

Авторы рассмотрели вопросы, связанные с находками кладов медных монет на территории Кыргызстана, обращавшихся в XV - начале XVI в. Цель статьи - введение в научный оборот новых типов медных монет династии Шейбанидов и методичное продолжение их последовательной каталогизации. Многие монеты пополнили список ранее известных типов, в частности несущих на себе зооморфные сюжеты. Авторы постарались собрать наиболее полную информацию о таких находках не только из научных публикаций, но и материалов собственных изысканий. Немногочисленные находки хорасанских и ферганских монет с зооморфными сюжетами дают возможность проследить устоявшиеся культурно-эстетические воззрения тюркоязычных народов. Публикация этих кладов дает основу для восстановления деталей и закономерностей денежного обращения в периферийных владениях Шейбанидов.

Ключевые слова: археология, Кыргызстан, Шейбаниды, нумизматика, медные клады, типы монет, ферганские города, зооморфные сюжеты, фулус, средневековая восточная нумизматика, денежное обращение

Обращение медных монет XVпервой четверти XVI в. детально исследовала Е.А. Давидович, но по ряду причин она не включила клады не мавераннахрского происхождения в свою фундаментальную монографию, полагая, что другие регионы Средней Азии будут изучены в будущем по мере поступления местного кладового материала [Давидович, 1983, c. 10]. Из Кыргызстана ею использован лишь Ошский клад, найденный в 1953 г. [Массон, 1960, с. 110-124]. В начале XXI в. стало известно о находках на территории Оша по крайне мере пяти кладов монет этого времени [Кочнев, 1998, с. 42-43].

В 1969 году в Ошский краеведческий музей поступило 1069 монет из клада, найденного в с. Мады. Основная масса монет отчеканена в Бухаре и Самарканде между 898 и
907 г.х., нескольким десятками представлены монеты Андигана и Ташкента, и единичными экземплярами Хисара, Герата, Балха, Шаша и Ахси. Самая «молодая» монета Бухары 911 г.х. [Шпенёва, 1987, с. 66-68; 2000, c. 104].

В 1997 году в Бишкек для изучения доставили клад из 980 медных монет, найденных в с. Чангыт ДжалалАбадской области Кыргызстана. Судя по годам на монетах (наиболее поздние отчеканены в 913/1507-08* году) [*Ранее время изъятия монет из обращения определялось по единственной монете в кладе, из-за плохой сохранности ошибочно датируемой 927/1521-1522; детальное изучение клада позволяет пересмотреть эту датировку], время его сокрытия выпадает на неспокойный, насыщенный социальными потрясениями 
Камымев А.М., Брагин А.О. Клады медных монет династии Шейбанидов на территории...

период истории. В конце XV века в ходе непрекращающихся междоусобиц наследники амира Тимура, разобравшие обширные владения своего предка на уделы, сменяли друг друга в столичном Самарканде чуть ли не ежегодно.

В Чангытском кладе преобладают выпуски Самарканда и Бухары, на третьем месте - монеты Андигана, бывшего в то время центром удельной Ферганы, в состав которой входил и район обнаружения клада. Продукция монетных дворов Ташкента и Хисара в кладе насчитывает около двух десятков, а монеты Хутталяна, Кеша, Герата, Шаша, Ахси и Яссы представлены единичными экземплярами [Камышев, 2002, с. 52].

Крупный клад медных монет начала XVI в., разбросанный селевым потоком по руслу сухой реки в Ляйлякском районе Баткенской области, был найден тремя детьми в 2000 г. Тогда юные краеведы разделили собранные медные кружочки между собой, но лишь один, повзрослев, догадался привезти монеты на определение специалистам в Бишкек. О первоначальном количестве монет в кладе можно судить приблизительно: доля одного из находчиков, представленная для изучения, составляет 2358 монет, а в 2011 г. на месте обнаружения клада с помощью металлоискателя поднято дополнительно ещё 587 монет. Монеты разобраны по месту и времени изготовления с указанием их количества в кладе, проиллюстрированы, измерены и взвешены, 883 экз. из-за плохой сохранности остались неопределёнными. Время сокрытия клада установлено по двум типам самаркандских монет с крайним годом выпуска 923 г.х. [Камышев, 2013, прил. 4].
Ляйлякский клад, относящийся по своему составу к седьмому этапу по периодизации Е.А. Давидович [Давидович, 1983, с. 301], представлен монетами среднеазиатского региона почти за столетний период истории. Судя по значительному количеству монет Ахси и Андигана 910-920 г.х., ранее учеными не зафиксированными, клад формировался в Ферганском уделе. Политическая обстановка в Фергане того времени была напряженной. Отданная в управление Шейбаниду Абу-л-Фатху Джанибек-султану в 910 г.х., она через шесть лет вновь отвоёвывается Тимуридами, а ещё через четыре года возвращается обратно под управление Шейбанидов. Столь крупные накопления, включающие монеты чекана более двух десятков городов, находящихся в руках враждующих между собой группировок, вряд ли связаны с межрегиональной торговлей, скорее всего, это военная добыча или армейская казна. Об этом свидетельствуют и десятки монет Герата и Кундуза, отчеканенные ещё до разграбления этих городов Шейбаниханом. Особый интерес в кладе вызвали монеты ферганских городов с зооморфными сюжетами [Камышев, 2011, с. 12-14] и ранее неопубликованные монеты Сайрама и Яссы [Камышев, 2012, с. 340-345].

Крупный клад медных монет найден при посадке деревьев в Аксыйском районе Джалал-Абадской области осенью 2011 г. Часть клада в количестве 220 монет привезена на определение в Бишкек. Из-за слабой сохранности и плотных окислов, покрывающих монеты, большая часть монетных типов осталась неопределённой. При беглом осмотре из партии были отобраны 20 наиболее со- 
хранившихся экземпляров, которые после очистки удалось разложить по типам, отсканировать и взвесить. Пару недель спустя родственник находчика привез ещё 37 экз., которые он самостоятельно очистил кислотой, уничтожив при этом практически все монетные надписи. Из этой партии типологически определены лишь три монеты. Еще одна часть клада в количестве 2128 экз. была доставлена в Бишкек в канун 2013 года, из которых удалось атрибутировать 1021 экз. [Камышев, 2013, с. 51-58]. Остатки этого клада в количестве 464 экз. авторам удалось обработать в октябре-ноябре 2016 г., из них надежно атрибутированы 280 экз. и еще 38 отнесены к чекану Ахси и Андигана без определения типа (табл. 1). Фотоизображения некоторых монет клада представлены на рис. 1, 2. Последние монеты не внесли заметных дополнений в уже опубликованную часть Аксыйкого клада. Самыми ранними монетами остались отчеканенные в Самарканде в 785 г.х., а к наиболее «молодым» монетам Бухары и Ахсы с годом 920 г.х. добавилась разновидность Самаркандской монеты (тип 25в), ранее в публикациях не зафиксированная. От типа 25 «а» и «б» она отличается орнаментом вокруг центрального ободка и реконструируемым годом выпуска как 920 г.х. Среди разнообразия монетных дворов в Аксыйском кладе выявлены ранее не отмеченные в публикациях монеты Вахша, Шапуркана, Бадахшана, Карши и Термеза (атрибуция выполнена А.О. Брагиным). Как и в первой части клада, где отмечены саманидский и караханидский фельсы, во второй выявлен стертый толстый монетный кружок, предположительно Кашгарский дирхам конца XII в. Повышенный процент наличия монет Ферганских городов Андигана и Ахси, а главное - почти одновременность выпадения из обращения с Ляйлякским кладом, позволяет нам предположить о происходивших значительных социально-политических потрясениях в этом регионе в конце первой четверти XVI в., вызвавших массовое сокрытие кладов населением.

Найденные в южных областях Кыргызстана крупные клады шейбанидской меди XV - начала XVI в. значительно пополнили ранее известный специалистам перечень монетных типов, особенно с зооморфными сюжетами. Введены в научный оборот новые монетные типы, продолжена каталогизация шейбанидской медной монеты, показано их многообразие, а также отмечено мастерство столичных резчиков матриц и, как правило, низкий его уровень в периферийных частях империи. Немногочисленные находки хорасанских и ферганских монет с зооморфными сюжетами дают возможность проследить устоявшиеся культурно-эстетические воззрения тюркоязычных народов, уходящие своими корнями в древнюю культуру сибирского звериного стиля. Публикация этих кладов дает основу для восстановления денежного обращения в периферийных владениях Шейбанидов.

Выявление новых комплексов медных монет, содержащих описанные типы, а так же единичных экземпляров позволит в дальнейшем подтвердить, дополнить и уточнить сделанные в ходе исследования выводы. 
Камышев А.М., Брагин А.О. Клады медных монет династии Шейбанидов на территории...
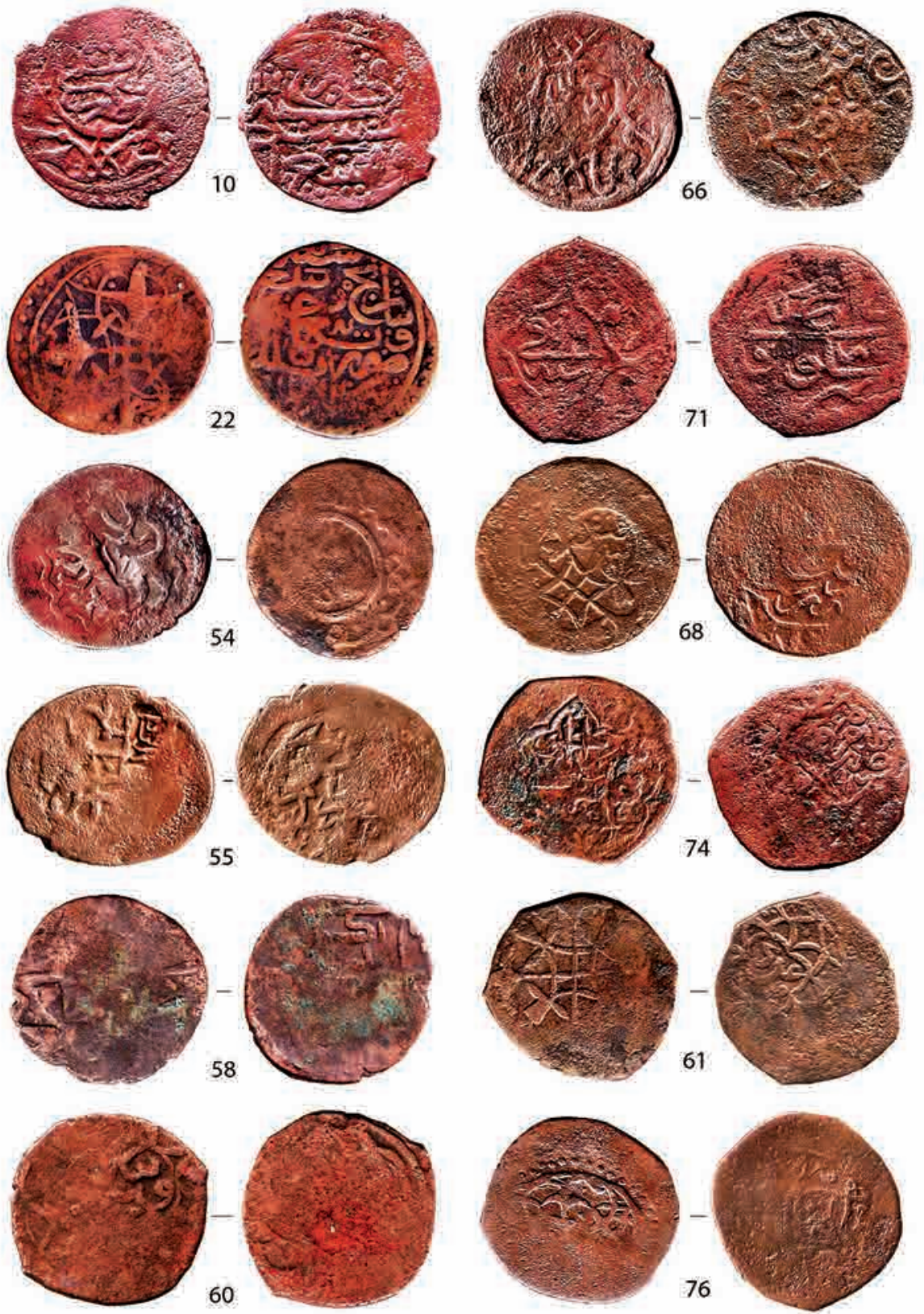

Рис. 1. Атрибуция некоторых монет из кладов Кыргызстана. 10 - Самарканд, 920 ? г.х.; 22 -монетный двор? (Бухара?), 917 г.х.; 54 -Хисар, б/д, надчекан не реконструируется; 55 - Хисар, б/д., надчекан «бито [в] Хисаре»; 58 - Ташканд, б/д.; 60 - Термез, б/д.; 66 - Бадахшан, б/д; 71 - Балх, 916 г.х.; 68 - Кундуз, б/д., надчекан «Самарканд»; 74 - Балдат Марв, 917 г.х.; 61 - Термез?, б/д.;

76 - монетньй двор не известен

Fig. 1. Attribution of some coins from the treasures of Kyrgyzstan. 10 - Samarkand, 920? AN; 22 - Mint? (Bukhara?), 917 AN; 54 - Hisar, b/d, the countermark is not reconstructed; 55 - Hisar, b/d., "Bito [in] Hisar" code; 58 - Tashkent, b/d.; 60 - Termez, b/d.; 66-Badakhshan, b/d; 71 - Balkh, 916 AN; 68 - Kunduz, b/d, Samarkand countermark;

74 - Baldat Marv, 917 AN; 61 - Termez ?, b/d.; 76 - Mint unknown 


\section{ҚАЗАКСТАН АРХЕОЛОГИЯСЫ № 1-2 2018}

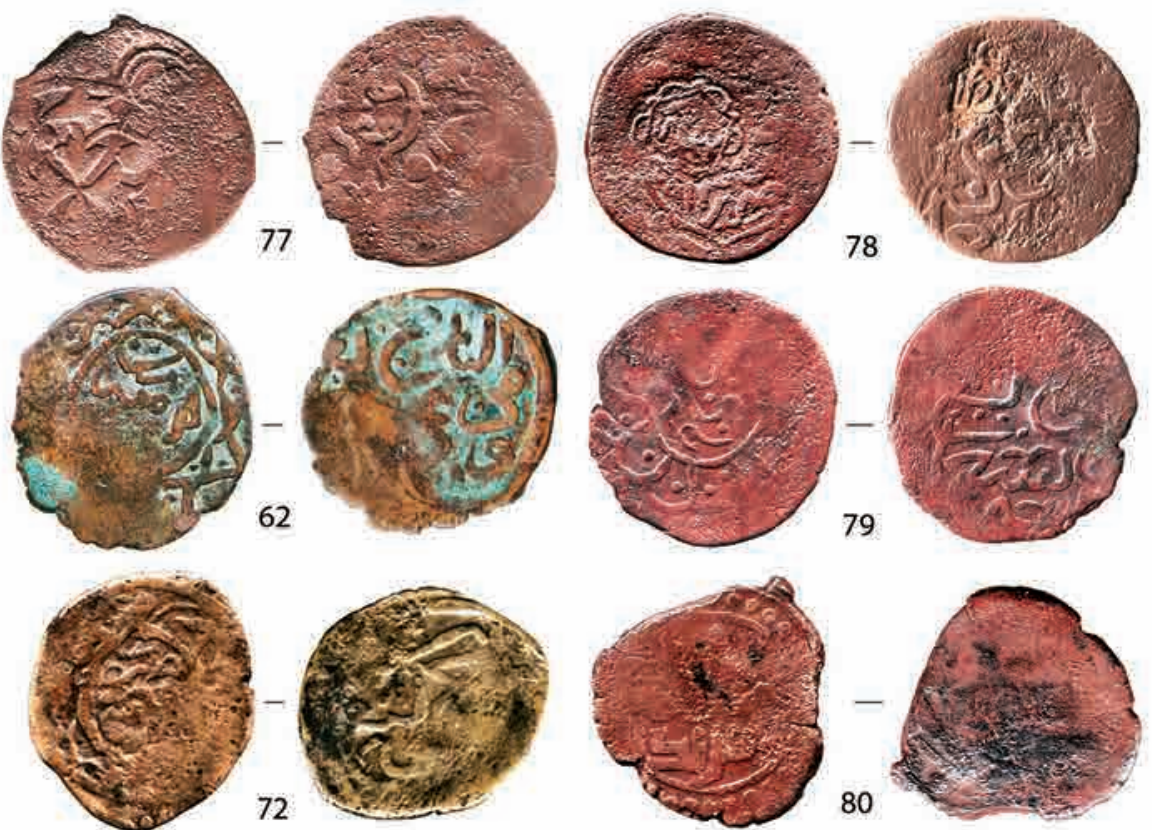

Рис. 2. Атрибуиия некоторых монет из кладов Кыргызстана 77 -монетный двор не известен; 62 - Термез?, 919 г.х.; 72 - Карии, 9хх г.х.; 78 -монетный двор не известен, 913 г.х.; 79 -монетный двор не известен, 9x9 г.х.;

80 - медная монета без атрибуциии

Fig. 2. Attribution of some coins from the treasures of Kyrgyzstan 77 - the mint is not known; 62 - Termez?, 919 AN; 72 - Karshi, 9xx AN; 78 - the mint is not known, 913 AN; 79 - the mint is not known, 9x9 AN; 80 - copper coin without attribution

Таблиияа 1

Типы монет Аксийского клада, часть 2

Table 1

Types of coins of the Aksiysky treasure, part 2

\begin{tabular}{|c|c|c|c|c|c|}
\hline \multirow{2}{*}{ № } & \multirow{2}{*}{ Тип } & Год, г.х. & Количество монет в & \multicolumn{2}{|c|}{ В том числе } \\
\cline { 4 - 5 } & & & кладе & без надчекана & с надчеканом \\
\hline
\end{tabular}

Самарканд
\begin{tabular}{|c|c|c|c|c|c|}
\hline 1 & 6 & 823 & 1 & 1 & - \\
\hline 2 & 96 & 897 & 11 & 1 & 10 \\
\hline 3 & 106 & 901 & 5 & - & 5 \\
\hline 4 & 13 & 906 & 3 & 1 & 3 \\
\hline 5 & 176 & 907 & 17 & 7 & 10 \\
\hline 6 & 19 & 911 & 1 & - & 1 \\
\hline 7 & 20 & 914 & 4 & 2 & 2 \\
\hline 8 & 22 & 917 & 7 & 4 & 3 \\
\hline 9 & $22 \mathrm{a}$ & 917 & 1 & - & 1 \\
\hline 10 & 25 в & 920 & 3 & 3 & - \\
\hline 11 & 29 & 918 & 17 & 14 & 3 \\
\hline 12 & 39 & б/д & 7 & 1 & 6 \\
\hline
\end{tabular}


Камымев А.М., Брагин А.О. Клады медных монет династии Шейбанидов на территории...

\section{Бухара}

\begin{tabular}{|c|c|c|c|c|c|}
\hline 13 & 3 & 832 & 2 & - & 2 \\
\hline 14 & $4 a$ & $89 x$ & 3 & - & 3 \\
\hline 15 & 56 & 897 & 6 & 1 & 5 \\
\hline 16 & $5 в$ & 897(?) & 1 & 1 & - \\
\hline 17 & $5 \mathrm{a}$ & 910 & 1 & - & 1 \\
\hline 18 & 8 & 907 & 1 & 1 & - \\
\hline 19 & 11 & $9 \mathrm{xx}$ & 1 & 1 & - \\
\hline 20 & 13 & 916 & 2 & 2 & - \\
\hline 21 & 14 & 917 & 3 & 2 & 1 \\
\hline 22 & $14 a$ & 917 & 1 & 1 & - \\
\hline 23 & 15 & 91x? & 2 & 2 & - \\
\hline 24 & 16 & 919 & 8 & 5 & 3 \\
\hline 25 & $16 \mathrm{a}$ & 919 & 19 & 16 & 3 \\
\hline 26 & 21 & б/д & 15 & 3 & 12 \\
\hline 27 & 26 & 920 & 1 & 1 & - \\
\hline
\end{tabular}

Axcu

\begin{tabular}{|c|c|c|c|c|c|}
\hline 28 & 2 & 910 & 1 & 1 & - \\
\hline 29 & $2 \mathrm{a}$ & 910 & 1 & 1 & - \\
\hline 30 & 3 & 910 & 2 & 6 & 1 \\
\hline 31 & 5 & б/д & 7 & 25 & - \\
\hline 32 & 6 & б/д & 25 & 8 & 1 \\
\hline 33 & 9 & б/д & 9 & 4 & - \\
\hline 34 & 10 & 920 & 5 & 4 & - \\
\hline 35 & 12 & б/д & 4 & 9 & - \\
\hline 36 & 13 & б/д & 37 & 2 & - \\
\hline 37 & 14 & 910 & 9 & 4 & - \\
\hline 38 & 15 & $907 ?$ & 2 & 1 & \\
\hline 39 & 16 & 920 & 4 & & \\
\hline 40 & 17 & б/д & 1 & & \\
\hline
\end{tabular}

\section{Андиган}

\begin{tabular}{|c|c|c|c|c|c|}
\hline 41 & 46 & $8 \mathrm{xx}$ & 2 & - & 2 \\
\hline 42 & 7 & //д & 4 & 4 & - \\
\hline 43 & 9 & б/д & 2 & 2 & - \\
\hline 44 & 10 & б/д & 2 & 2 & - \\
\hline 45 & 11 & б/д & 2 & 2 & - \\
\hline 46 & 12 & б/д & 3 & 3 & \\
\hline
\end{tabular}

\section{Xucap}

\begin{tabular}{|c|c|c|c|c|c|}
\hline 47 & $7 \mathrm{a}$ & $918-17$ & 11 & 6 & 5 \\
\hline 48 & 76 & б/д & 2 & 1 & 1 \\
\hline 49 & 8 & $91 \mathrm{x}$ & 1 & 1 & - \\
\hline 50 & 9 & б/д & 1 & - & 1 \\
\hline 51 & 16 & б/д & 2 & 1 & 1 \\
\hline 52 & $21 \mathrm{a}$ & 890 & 2 & 2 & - \\
\hline 53 & 22 & б/д & 1 & 1 & - \\
\hline 54 & 23 & б/д & 1 & - & 1 \\
\hline 55 & 24 & б/д & 1 & - & \\
\hline
\end{tabular}

Тамканд

\begin{tabular}{|c|c|c|c|c|c|}
\hline 56 & 2 & $89 x$ & 1 & 1 & - \\
\hline 57 & 5 & б/д & 1 & 1 & - \\
\hline 58 & 13 & б/д & 1 & 1 & - \\
\hline
\end{tabular}


Термез

\begin{tabular}{|l|l|l|l|l|l|}
\hline 59 & 1 & 832 & 1 & 1 & - \\
\hline 60 & 3 & $\mathrm{xxx}$ & 1 & 1 & - \\
\hline 61 & 4 & б/д & 1 & 1 & - \\
\hline 62 & 5 & 919 & 1 & 1 & - \\
\hline
\end{tabular}

Фаркат

\begin{tabular}{|c|c|c|c|c|c|}
\hline 63 & 5 & б/д & 1 & - & 1 \\
\hline \multicolumn{6}{|c|}{ Хутталан } \\
\hline 64 & 4 & б/д & 1 & 1 & - \\
\hline 65 & 7 & б/д & 2 & 2 & - \\
\hline
\end{tabular}

\section{Бадахшан}

\begin{tabular}{|c|c|c|c|c|c|}
\hline \begin{tabular}{|l|}
66 \\
\end{tabular} & 2 & б/д & 1 & 1 & - \\
\hline \multicolumn{6}{|c|}{ Кундуз } \\
\hline 67 & 2 & б/д & 1 & - & 1 \\
\hline 68 & 5 & б/д & 1 & - & 1 \\
\hline
\end{tabular}

\section{Kem}

\begin{tabular}{|c|c|c|c|c|c|}
\hline \begin{tabular}{|l|}
69 \\
\end{tabular} & 2 & б/д & 2 & 1 & 1 \\
\hline \multicolumn{6}{|l|}{ Ясcbl } \\
\hline 70 & 1 & б/д & 1 & 1 & - \\
\hline \multicolumn{6}{|l|}{ Балх } \\
\hline 71 & 10 & 916 & 1 & 1 & - \\
\hline \multicolumn{6}{|c|}{ Карши } \\
\hline 72 & 5 & $9 x x$ & 1 & 1 & - \\
\hline \multicolumn{6}{|c|}{ Камгар } \\
\hline 73 & 1 & 858 & 1 & - & 1 \\
\hline \multicolumn{6}{|l|}{ Мерв } \\
\hline \begin{tabular}{|l|}
74 \\
\end{tabular} & $8 \mathrm{a}$ & 917 & 1 & 1 & - \\
\hline
\end{tabular}

Неотределенные монетные типь
\begin{tabular}{|c|c|c|c|c|c|}
\hline 75 & 3 & 919 & 2 & - & 2 \\
\hline 76 & 32 & б/д & 1 & 1 & - \\
\hline 77 & 33 & б/д & 1 & - & 1 \\
\hline 78 & 34 & $? ? ?$ & 1 & 1 & - \\
\hline 79 & 35 & $9 \times 9$ & 1 & 1 & - \\
\hline 80 & - & $\begin{array}{c}\text { Конец } \\
\text { ХІІ в. }\end{array}$ & 1 & 1 & - \\
\hline
\end{tabular}

Примечание: в иллюстрациях монеты помещены под теми же номерами, что и в таблице. Обозначение: б/д - без года.

\section{ЛИТЕРАТУРА}

1. Давидович E.A. История денежного обращения средневековой Средней Азии (медные монеты XV - первой четверти XVI в. в Мавераннахре). М.: Наука, 1983. $359 \mathrm{c}$.

2. Камышев А.М. Нумизматическое наследие Кыргызстана. Альбом. Бишкек: Национальный Банк Кыргызской Республики, 2002. 128 с.

3. Камылее А.М. Новые типы и разновидности шейбанидских монет Ахсикета и Андигана // Нумизматика. 2011. № 2 (май). С. 12-14.

4. Камышев А.М. Новые типы шейбанидских монет Яссы и Сайрама // Древности Отрара и Отрарского оазиса Казахстана и Евразии: матер. междунар. научн.практ. конф., посвящ. 40-летию ЮККАЭ (Шаульдер, 18-19 октября 2011 г.). Алматы: Институт археологии им. А.Х. Маргулана, 2012. С. 340-345. 
Камышев А.М., Брагин А.О. Клады медных монет династии Шейбанидов на территории...

5. Камышев А.М. Клады медных монет Тимуридов и Шейбанидов. Самарканд: МИЦАИ, 2013. $176 \mathrm{c.}$

6. Кочнев Б.Д. Средневековый Ош в свете нумизматики // Изучение древнего и средневекового Кыргызстана. Бишкек: «Мурас»,1998. С. 42-43

7. Массон M.E. Клад медных монет XV века из Оша // Эпиграфика Востока. 1960. T. XIII. C. 110-124.

8. Шпенёва Л.Ю. Новые клады медных монет XV - начала XVI в. из Ферганы // Вторая нумизматическая конференция: тез. докл. и сообщ. М., 1987. С. 66-68.

9. Шnенёва Л.Ю. Клад медных тимуридских монет из села Мады Ошской обл. // Ош и Фергана в исторической перспективе. Бишкек: «Мурас», 2000. Вып. 3. C. 103-104.

\section{Сведения об авторах:}

Камышев Александр Михайлович - кандидат исторических наук, преподаватель, Кыргызско-Российский университет (г. Бишкек, Кыргызстан); sakmih@mail.ru

Брагин Андрей Олегович - аспирант, Центр исследований истории Золотой Орды, Институт истории им. Ш. Марджани, г. Казань (г. Санкт-Петербург, Россия); rasmir@mail.ru

\section{ҚЫРҒЫЗСТАН АУМАҒЫНДАҒЫ ШЕЙБАНИДТЕР ӘУЛЕТІ ЖЕЗ ТИЫНДАРЫНЫН КӨМБЕЛЕРІ}

\section{А.М. Камышев, А.О. Брагин}

Мақала авторлары Қырғызстанда табылған көмбелердегі XV және XVI ғасырдың басында айналымда болған жез тиындар мәселелерін қарастырады. Мақала мақсаты Шейбанидтер әулетінің жез тиындарының жаңа түрлерін ғылыми айналымға енгізу және жүйелі зерттеулер арқылы каталогтау болып табылады. Көптеген тиындар бұрыннан белгілі тиын түрлерінің тізімін толықтырады, мысалға зооморфты сюжеті бар тиындарды атап өтуге болады. Авторлар осындай олжалар туралы толыққанды ақпараттарды ғылыми жарияланымдардан ғана емес, жеке ізденістерінің материалдары арқылы жинастыруға тырысқан. Зооморфты сюжеті бар хоросандық және ферғаналық тиындардың азын-аулақ табылғандары түркітілдес халықтардың мәдениэстетикалық танымдарын бақылауға мүмкіндік береді. Көмбе материалдарын жариялау шейбанидтер иеліктерінің шеткері аймақтарындағы ақша айналымының кейбір тұстары мен заңдылықтарын қалпына келтіруге негіздеме бола алады.

Түйін сөздер: археология, Қырғызстан, шейбанидтер, нумизматика, жез көмбелер, тиын түрлері, Ферғана қалалары, зооморфты сюжеттер, фулус, ортағасырлық шығыс нумизматикасы, ақша айналымы

\section{HOARDS OF COPPER COINS OF SHAYBANID DINASTY IN THE KYRGYZSTAN}

\section{A.M. Kamyshev, A.O. Bragin}

The article touches upon the issues related to the finds of copper coin hoards on the territory of Kyrgyzstan circulating in the 15th - early 16th centuries. The purpose of the article is to introduce new types of copper coins of the Shaybanid dynasty into the scientific circulation and methodically continue their sequential cataloging. Many coins have enlarged the list of previously known types, in particular, bearing zoomorphic plots. The authors tried to collect the most complete information about such finds not only from scientific publications, but also on the materials of their own research. The few finds of Horasan and Fergana coins with zoomorphic plots make it possible to trace the established cultural and 
aesthetic views of the Turkic-speaking peoples. The publication of these hoards provides the basis for restoring the details and regularities of money circulation in the peripheral possessions of the Shaybanids.

Keywords: archaeology, Kyrgyzstan, Shaybanids, numismatics, copper hoard, types of coins, Fergana cities, zoomorphic stories, fulus, medieval east numismatics, monetary circulation

\section{REFERENCES}

1. Davidovich, E. A. 1983. Istoriya denezhnogo obrashcheniya srednevekovoy Sredney Azii (mednye monety XV-pervoi chetverti XVI v. v Maverannahre) (The history of monetary circulation in medieval Central Asia (copper coins of the 15th century - the first quarter of the 16th century in Maverannahr). Moscow: Nauka Publ. (in Russian).

2. Kamyshev, A. M. 2002. Numizmaticheskoe nasledie Kyrgyzstana. Al’bom. (Numismatic heritage of Kyrgyzstan. Album). Bishkek: National Bank of the Kyrgyz Republic (in Russian). Russian).

3. Kamyshev, A. M. 2011. In Numizmatika (Numismatics), 2 (May), 12-14 (in

4. Kamyshev, A. M. 2012. In Baipakov, K. M. (ed.) Drevnosti Otrara i Otrarskogo oazisa Kazahstana i Evrazii (Antiquities of Otrar and the Otrar oasis of Kazakhstan and Eurasia). Almaty: Archaeology Institute after A.Kh. Margulan, 340-345. (in Russian).

5. Kamyshev, A. M. 2013. Klady mednyh monet Timuridov $i$ Sheybanidov (Treasures of Timurid and Sheibanid copper coins). Samarkand: MICAI (in Russian).

6. Kochnev, B. D. 1998. In Izuchenie drevnego i srednevekovogo Kyrgyzstana (Study of ancient and medieval Kyrgyzstan). Bishkek: «Muras» Publ., 42-43 (in Russian).

7. Masson, M. E. 1960. In Epigrafika Vostoka (Epigraphic of the East), XIII, 110-124 (in Russian).

8. Shpenyova, L. Yu. 1987. In Vtoraya numizmaticheskaya konferenciya (Second numismatic conference). Moscow, 66-68 (in Russian).

9. Shpenyova, L. Yu. 2000. In Osh i Fergana v istoricheskoy perspective (Osh and Fergana in historical perspective), 3. Bishkek: «Muras» Publ., 103-104 (in Russian).

\section{About the Authors:}

Kamyshev Alexander M. Candidate of Historical Sciences, Lecturer, KyrgyzRussian University, Bishkek, Kyrgyzstan; sakamih@mail.ru

Bragin Andrey O. Post-graduate student, Sh. Mardzhani Institute of History, Tatarstan Academy of Sciences, Saint-Petersburg, Russia; e-mail: rasmir@mail.ru

\footnotetext{
Мүдделер қақтығысы туралы ақпаратты ашу. Авторлар мүдделер қақтығысының жоқтығын мәлімдейді. / Раскрытие информации о конфликте интересов. Авторы заявляют об отсутствии конфликта интересов.

/ Disclosure of conflict of interest information. The authors claims no conflict of interest.

Мақала туралы ақпарат / Информация о статье / Information about the article. Редакцияға түсті / Поступила в редакцию / Entered the editorial office: 15.08.2018. Рецензенттер мақұлдаған / Одобрено рецензентами / Approved by reviewers: 22.08.2018 Жариялауға қабылданды / Принята к публикации / Accepted for publication: 29.08.2018.
} 